\title{
Environmental Migration: Social Work at the Nexus of Climate Change and Global Migration
}

\author{
Meredith C. F. Powers \\ Cathryne L. Schmitz \\ Christian Z. Nsonwu \\ Manju T. Mathew
}

\begin{abstract}
Environmental migrants are caught at the nexus of the climate crisis and the global migrant crisis. The problems of the migrant crisis are recognized globally as they are linked to the complex issues being addressed by the United Nations' Sustainable Development Goals. The complexity of the issues makes it difficult to grasp the breadth and depth of this crisis. As a result, it can be understood as one of the "wicked problems" requiring us to respond through a lens that recognizes the interconnections of humans and the broader ecosystems within the physical surroundings. When approaching the migrant crisis from this perspective, professionals are challenged to create transdisciplinary, community-based response systems which are holistic, multi-pronged, and inclusive of migrants' voices and strengths. Storytelling provides a venue for highlighting migrants' voices, engaging in change, and creating the space for individual and collective healing. Social workers are increasingly being called upon to become trained in this practice and to engage in complex change systems alongside other disciplines and community members. As they provide prevention, mitigation, resettlement, and relief efforts, social workers become a part of a global community of leaders engaged in transformative change. By working to address these challenges, they are securing a better world not only for environmental migrants, but also for our planet as a whole.
\end{abstract}

Keywords: Environmental migrants; climate crisis; indigenous biophilia framework

Climate change and environmental degradation, significant factors of the climate crisis, precipitate deteriorating environmental, political, and economic systems that are creating a global migrant crisis (Besthorn \& Meyer, 2010; Black et al., 2011; Brown, 2008; Drolet, 2017; United Nations High Commission on Refugees [UNHCR], 2009). In fact, climate change has been acknowledged as the most significant threat to present and future generations of the global community, creating unprecedented migration (UNHCR, 2009; UN Environment, 2016; UN Trust Fund for Human Security, n.d.). Such threats from natural occurrences include the slow onset of environmental degradation, as well as extreme weather patterns and correlating droughts, desertification, storms, volcanic eruptions, earthquakes, tsunamis, and rising sea levels. These threats are exacerbated by human behaviors in two ways: (a) in our contribution to global warming and toxic environments, and (b) in the way we create built environments in areas that are at risk for such threats and yet are unequipped for and/or biased in the way we address the devastation of such crises when they occur. Thus, the problem of the global migrant crisis lacks

Meredith C. F. Powers PhD, MSW is an Assistant Professor, School of Social Work, University of North Carolina Greensboro, Greensboro, NC 27402. Cathryne L. Schmitz, PhD, MSW is a Professor Emerita, School of Social Work, University of North Carolina Greensboro, Greensboro, NC 27402. Christian Z. Nsonwu, BA, is a MSW student, School of Social Work, University of North Carolina Greensboro, Greensboro, NC 27402. Manju T. Mathew, MA, Women and Gender Studies, University of North Carolina Greensboro, Greensboro, NC 27402. 
recognition of the interconnections of humans and the broader ecosystems. Approaching the migrant crisis in its complexity, challenges social workers and other professionals to create response systems which are inclusive of migrant voices, vulnerabilities, and strengths while validating the environmental crisis that precipitates this migration crisis. This requires tackling climate change and the resulting migration crisis simultaneously.

Estimates of the number of environmental migrants vary widely; ranging from 25 million to 1 billion, with the most widely accepted estimate of 200 million (Intergovernmental Panel on Climate Change [IPCC], 2015; International Organization for Migration [IOM], 2018b). As defined by the IOM, environmental migrants are those displaced and/or migrating as a result of natural and human-made disaster events, as well as ongoing, deteriorating environments that create conditions that are not sustainable for life (IOM, 2018a). They experience significant loss and trauma, but in many instances, are resilient and make remarkable recoveries (Weng \& Lee, 2016).

Although all persons moving for environmental reasons are protected by international human rights law, these rights are often not easily upheld, in transit or in relocation. Persons displaced within their country of origin due to natural or human made disasters, are covered by provisions laid out in the Guiding Principles on Internal Displacement (IOM, 2015). Environmental migrants are further recognized officially by the IOM as:

...persons or groups of persons who, for reasons of sudden or progressive changes in the environment that adversely affect their lives or living conditions, are obliged to have to leave their habitual homes, or choose to do so, either temporarily or permanently, and who move either within their territory or abroad. (IOM, 2018a, para. 1)

This definition acknowledges that environmental migrants are forced to leave, or decide by choice to migrate, due to deteriorating environmental conditions and extreme environmental events; this may occur within and/or across international borders for brief, prolonged, or permanent periods of time (IOM, 2015). Thus, while the term environmental refugee continues to be a matter of debate, for purposes of this article, we will use the term environmental migrants to refer to those who migrate due to environmental perils, regardless of their legal status as refugees.

Environmental migrants are a diverse group and some are eligible to receive legal refugee status due to other displacement criteria. Current international policies, however, do not include climate change and environmental hazards as the basis of becoming a refugee, and the term environmental refugee is not a legal term or status (UNHCR, 2016). The way in which some migrants' hardships are legally recognized and thus provided with aid and resources, while others are excluded (e.g., environmental hardships), is one aspect of the complexity.

Social workers play instrumental roles in helping environmental migrants overcome the challenges faced at each stage of their journeys, from working to mitigate climate change issues that cause displacement, to helping rebuild and reestablish people in their homes of origin, to assisting with resettlement and building new lives, and to being advocates to change the policies and laws to include environmental refugees (Powers \& 
Nsonwu, in press; Drolet, 2017). While addressing issues faced by environmental migrants, social workers not only collaborate with professionals in the social and natural sciences, but also with communities around the globe to address the United Nations' Sustainable Development Goals (IFSW, 2017).

According to the Global Agenda for Social Work and Social Development, professional social workers are to promote community and environmental sustainability while also advocating for social and economic equality, the dignity and worth of all peoples, and attending to the importance of human relationships (International Association of Schools of Social Work, International Council on Social Welfare, and International Federation of Social Workers [IASSW, ICSW, \& IFSW], 2012). Social workers, as interdisciplinary partners, are able to address these four interwoven agenda items in addition to the United Nations' Sustainable Development Goals through providing leadership on climate advocacy and action, and by working with environmental migrants to rebuild their lives.

\section{The Interwoven Complexity of the Global Climate and Migrant Crises}

Environmental migration occurs at the nexus of complex and interwoven concerns: the global climate crisis and the global migrant crisis. These problems are so large, complex, and interconnected that they cannot be solved, but due to their nature we have to intervene; these crises therefore fit Kolko's (2012) definition of a wicked problem. They have many causes, ongoing processes of spiraling change, complex social interactions, multiple interpretations, conflicting goals, and an interdependency further complicated by the transnational nature of the issues. In attempting change, it is necessary to recognize that there is no one solution and there is great potential for unforeseen consequences (Brown, 2010). Although the climate crisis and the migrant crisis are interwoven, environmental migrants have little recognition globally of their status as migrants with legitimate human rights claims for permanent resettlement because the intersection is not validated.

This century, the world is facing a global climate crisis with issues of sustainability due to overpopulation, overcrowded cities, the depletion of environmental resources, limited food supplies, and pollution of air, water, and land (Brown, Deane, Harris, \& Russell, 2010). Climate science has established the contributing role of human behavior in global warming; $97 \%$ of climate scientists are in agreement (Cook et al., 2016). Further, humans have been frustrated as they have struggled to increase food and energy production (Brown et al., 2010). "It is the sum of the local issues that has generated the global issues in the first place. Thus, we can appear to be locked in an endless spiral from which there is no escape" (Brown et al., 2010, p. 3). These social-environmental problems cannot be solved with the tools of the last century These are not individual issues, but rather have implications inclusive of communities, regions, and countries devastated by environmental change. While there are no final solutions, transformative change will require validation of the degradation and an understanding of the collective impact and context for change.

Experts warn that the climate crisis will exacerbate environmental migration well beyond what we have previously seen (Taylor, 2017). The migrant crisis as enmeshed with the climate crisis is further aggravated by conflicts that erupt due to depleted resources 
along with related economic, social, and environmental injustices (IPCC, 2015). "Environmental justice occurs when all people equally experience high levels of environmental protection and no group or community is excluded from the environmental policy decision-making process, nor is affected by a disproportionate impact from environmental hazards" (Council on Social Work Education [CSWE], 2015, p. 20). The impact of the climate crisis is further intertwined with issues of violent conflict; cultural, economic, and environmental injustice; and displacement. In a study conducted in 2015, evidence showed that the effects of global climate change have sparked armed conflict; it has significantly contributed to the armed conflict and eventual civil war in Syria (Kelley, Mohtadi, Cane, Seager, \& Kushnir, 2015; Welch, 2015). This evidence points to the spiraling nature of the issues and to the concepts many scholars have theorized for years, that the scarcity of resources (i.e., food, shelter, water) lead to major violent conflicts as the effects of climate change worsened.

Environmental migrants often flee their homes of origin due to violent conflict and/or because they face hardships (e.g., starvation) that result from climate change and prolonged conflict. Their experience of loss is multi-layered, including the loss of family, friends, and home as well as the general comfort of the familiar, including culture and language, which impact whole communities. The sights, sounds, relationship patterns, interactions, structures, language, and communication patterns of their new surroundings are unfamiliar (Deepak, 2018; Powers \& Nsonwu, in press).

Demographic factors influence the need for and path of migration. "It is incumbent upon professionals committed to social and economic justice, to comprehensively understand the range of obstacles facing immigrants and refugees and empower them in their struggle to make a healthy adjustment" (Schmitz, Vazquez Jacobus, Stakeman, Valenzuela, \& Sprankel, 2003, p. 135). Vulnerable populations are more burdened by environmental degradation and climate change; as a consequence, these influences are more prevalent in the migrant crisis. An expanded analysis thus considers how demographics not only influence who migrates, but also explores more deeply why they are at higher risk and consequently more likely to migrate. Populations at highest risk and most heavily impacted include populations of color, those in the Global South, low economic status, and women and children (Alston, 2013; Parry, Canziani, Palutikof, Linden, \& Hanson, 2007; United Nations Women Watch, 2009). Gender, race, economic status, and religion are closely linked to the discrimination faced by migrants before, during, and after migration (Soylu \& Buchanon, 2013). The history of displacements and fear that compound the transitions faced by migrants (Devore \& Schlesinger, 1998; Schmitz et al., 2003) is further aggravated for women and girls, especially women and girls of color (Lie \& Lowery, 2003).

In order to address the complexity, the analysis needs to be expanded to include the multiple, intersecting issues. As migrant communities share their stories, our understanding of their experience of loss and trauma takes shape; the claiming of collective agency has a role in framing the healing process. Environmental migrants have too often been subjected to chronic injustices, which are then exacerbated by environmental disasters. For example, in Sri Lanka people who were fighting against waste being dumped in their communities then endured a massive landslide, which wiped out over 100 homes in the area and resulted 
in many losing their lives (Reuters and The Associated Press, 2017). Another tragic example includes the hurricanes that devastated families' homes and livelihoods in Puerto Rico creating displacements and environmental migrations. These communities were already vulnerable socially, politically, and economically due to extreme environmental injustices from the hazards of 23 Superfund sites, former US military bomb test sites, and local corporate waste of coal ash; these hazards were exacerbated by the hurricane damage (Atkin, 2017).

Kenya is a country that has faced significant hardships including climate change, environmental migration, political violence, and loss of the ecology for supporting food production and a clean water supply (Opido, Odwe, Oulu, \& Omollo, 2017). Because wicked problems, as they overlap, have no single answer, we must therefore embrace multi-pronged processes and systems for change that are inclusive of the local community (Balint, Stewart, Desai, \& Walters, 2011). Wangari Maathai modeled the multi-pronged approach to change as she addressed the interconnection of environmental, social, and political problems. It was in her community that she began her path as an activist and change agent to rebuild the ecosystem, repair the fundamental connections of people to their environment, and overcome political violence. She began the process by working locally on very practical issues and building community and collective change in the process. This served to mitigate the need to migrate. She was able to see beyond the immediate presenting problems in the community to address them holistically, taking into account all of their complexity. As the ecosystem healed, so did the community. She poignantly stated,

Recognizing that sustainable development, democracy and peace are indivisible is an idea whose time has come... Today we are faced with a challenge that calls for a shift in our thinking, so that humanity stops threatening its life-support system. We are called to assist the Earth to heal her wounds and in the process heal our own - indeed to embrace the whole of creation in all its diversity, beauty and wonder. (Maathai, 2004, para. 7, 22)

Wangari Maathai grew up in a village in Kenya that had a vibrant and self-sustaining ecosystem. When she returned home after completing bachelor's and master's degrees in biology in the United States, she found an ecosystem that had collapsed. In Kenya, she completed her Ph.D., becoming the first woman in East Africa to earn a doctorate. She engaged the women of the community in germinating, growing, and planting trees. Because she was only organizing women, she was ignored by the repressive, patriarchal government. This project blossomed into the very successful Green Belt Movement (Maathai, 2003; Merton \& Dater, 2008); at the point that it was apparent that an effective movement was taking root, she (and the movement) became a threat, engendering a violent response. The movement occurred at the nexus of multiple struggles, including climate change, environmental degradation, gender oppression, and violent conflict with governmental oppression (Strides in Development, 2010). The women stood boldly in the face of violence, and engaged the community to challenge the repression; through her work, Maathai was the first woman in Africa to win the Nobel Peace Prize in 2004. Maathai created a movement with multiple threads that promoted processes engaging civic 
dialogue, critical assessment, and mechanisms that facilitated the empowerment of the community toward transformative change (Strides in Development, 2010).

\section{Lens for Critical Exploration and Engagement}

The migrant crisis, approached as a communal problem, can be more deeply understood by including the broader social, political, and biophysical context into our analysis. Like all such complex struggles, intervention failures often result because the nature of the problem is not understood and therefore responses are off target (Watkins \& Wilber, 2015). Problems cannot be solved "with the same level of thinking that created the problems - we need a new level of thinking. The first step to bringing a new level of understanding to the nature of these complex issues is to dissect the features of extremely complex, difficult, or 'wicked problems"” (Watkins \& Wilber, 2015, p. 4). Engaging holistic, collective, and complex frameworks for action supports the potential for creating systems and processes for change within communities. Life on earth is not just composed of interactions between humans, but also includes the interconnectedness of humans, entire ecosystems, and the physical environment. Life here denotes countless species of flora and fauna that live on the planet; all things, living and non-living, human and other than human, are connected in the large matrix of life on earth (Canty, 2017).

It is this interactive relationship of life within a physical space/place that forms the backdrop for the development of the biophilia framework. The term "biophilia" was first used by Harvard Zoologist E. O. Wilson (1984) to describe "the innate human urge to affiliate with other forms of life" (p. 85). Use of the biophilia framework expands the depth of analysis for the migrant crisis by helping us to recognize the interconnectedness of species with each other and with the ecosystem/environment (Lysack, 2010; Rabb, 2017). Destruction of the ecological environment, negatively impacts the quality of human life materially, psychologically, and spiritually (Kellert \& Wilson, 1995).

Biophilia involves an awareness of the interconnectedness of nature and understands the role of humans as only one aspect in nature. Dr. Maathai's work exemplifies the application of this framework. Analytic assessment with a biophilia framework involves not just accounting for a physical place inclusive of sun, wind, rain, land, lakes, rivers, and oceans, but also the components of spiritual relationship to a place, a sense of belonging to the local components of nature and understanding their importance and striving to respect these aspects (Lysack, 2010; Rabb, 2017). It is the well-being of these relationships that creates and sustains life on this planet. Environmental degradation and climate change is resulting in a loss of a species and altered landscapes, and thus is a pivotal, precipitating factor in the migrant crisis. Understanding these connections and trying to address aspects of the biophysical context through a biophilia framework allows us to more critically analyze and mitigate the migrant crisis.

As a prime example, water is often referred to biologically as an inanimate aspect, yet, water is life. Humans rely on water for our personal consumption, and without it would surely die within a few days (Packer, 2002). Communities rely on water for our agriculture, household needs, and countless other purposes. In addition, water provides a context for life for many species, and water in many forms of weather slowly and dramatically shapes 
and reshapes landscapes. Global changes to the environment severely affect seawater and air temperatures, creating glacial melting and creating a significant sea level rise over the past century (Garner, 2015). Shifts in ocean currents and large weather events off continental coastlines have major impacts including hurricanes, cyclones, and typhoons. These storms can have a dramatic impact from heavy rainfall, flooding, storm water surges, and high winds, even if they do not make landfall. Such events not only harm human and other forms of life, but also alter the entire ecosystem and physical space, many times creating the need for environmental migration.

Humans have always oriented themselves by establishing a direct, personal, and communal relationships to places in the landscapes with which they have interacted (Cajete, 1999). It is the well-being of these relationships that can sustain or denigrate life on this planet. While the biophilia framework embraces the connection of people to place and the nature, inclusive of all life (Besthorn \& Saleeby, 2003), indigenous biophilia, further explicates and emphasizes these links while also adding the additional layers of oppression and power dynamics across culture, place, and nature (Cajete, 1999). Through an indigenous biophilia lens, complex change systems can be embraced. For example, indigenous biophilia knowledge is increasingly acknowledged "as valuable for adaptation to climate change" (Williams \& Hardison, 2013, p. 531); there is some concern, however, about humankind's ability to adapt are strained given how rapid the changes are occurring (McLean, 2010).

Indigenous biophilia knowledge, in recognizing the link of people with place, nature, community, and tradition (Cajete, 1999), promotes respect for human and other than human and mindfulness when creating change, even small changes, as they can have drastic consequences for the entire ecosystem. The cultural activities, traditions, and stories of one's own community reflect the context for social and environmental relationships (Cajete, 1999). The specifics are understood in relation to the whole, and the principles are experienced within everyday circumstances (Kawagley \& Barnhart, 1999). Indigenous biophilia sets the framework for ecological transformation (Cajete, 1999) as well as a context for exploring tribal oppression and engaging resistance (Norgaard \& Reed, 2017). Decline in the natural world is related to social and political disruptions (Colomeda, 1999; Norgaard \& Reed, 2017), in turn creating more environmental migrants.

\section{Engaging Complex Change Systems}

Approaching environmental migration, and the overarching global migrant crisis as a wicked problem highlights the complexity of the issues, challenging us to think beyond simplistic uni-dimensional interventions. Without embracing a holistic overview, the need to engage in complex, transformative processes and systems of change can be glanced over (Bradshaw, 2009). Vulnerable and marginalized prior to migration, individuals, families, and communities seeking refuge too often face additional struggles as their safety and status is further marginalized on the journey. Thus, the global migrant crisis requires multipronged systems of response that are inclusive of the collective and individual voice of the migrants. While environmental migrants confront unique risks as historically marginalized groups, they also present individual and collective strengths such as agency, resilience, and the potential for healing (Weng \& Lee, 2016). 
The power for collective healing should not be overlooked in developing systems of response to the migrant crisis. Social healing and resilience can be built in communities experiencing sustained violence (Lederach \& Lederach, 2010). The building of resilience is linked to strengths, temperament, and environmental context (Hutchinson, Stuart, \& Pretorius, 2010) with studies highlighting the importance of social connection for building community resilience (Ellis \& Abdi, 2017). The agency and power of environmental migrants is recognized and becomes a base for empowerment thru policy action: "The meaningful participation of immigrants and refugees in challenging immigration and labor policies is in itself a path toward healing" (Deepak, 2018, p. 120).

Gendered risk factors and the promotion of healing through the empowering quality of collective resistance can be analyzed through the lens of postcolonial feminism (Deepak, 2018), which is inclusive of the voices of indigenous women and critical reflection of racial domination (Spurlin, 2010). The postcolonial feminist perspective provides a framework for rethinking "the risk factors for poor mental health as embedded in oppressive structural, historical, and political factors rather than solely in individual experiences" (Deepak, 2018, p. 120). Response processes and systems with environmental migrants that focus on deficits, dependency, and models of helplessness negate the potential impact of collective agency in the change process (Weng \& Lee, 2016). The experiences and transnational context facing immigrants impact health and mental health promoting or compromising mental health (Deepak, 2018). These factors impact the individual and collective resilience reinforcing the need for community leadership.

\section{Community Embedded Healing}

Communities are sites for collective action, holding the potential to function as spaces for transformative change. Through collaborative community development, individual and communal issues can be interconnected creating the potential to support holistic models of sustainable change (Orr, 2004). While the meaning of community varies widely at the local and global levels, community remains the context for organizing, developing, and changing social, economic, and political systems (Gamble \& Weil, 2010). "Neighborhood and community organizing takes place when people have face-to-face contact with each other, allowing them to feel connected to a place" (Gamble \& Weil, 2010, p. 122). Communities are rich in the resources necessary for healing and recreating home, offering with the possibility for supporting sustainable development and addressing climate change. The impact of the Greenbelt Movement (Merton \& Dater, 2008) as the beginning process for community development provides lessons on community and environmental healing. Within the indigenous biophilia framework, it is understood that community and environmental healing and sustainability, at the local and global levels, depends on respect for and maintenance of the Earth's ecosystems, which forms the basis for the wellbeing of current and future generations (Cajete, 1999; Kellert \& Wilson, 1995; Lysack, 2010; Rabb, 2017; Sustainable Human, 2014).

Healing is facilitated when collective narratives are explored and respected. Storytelling can be used at the community level to develop and redevelop narrative. The voice of environmental migrants can be recognized and empowered through storytelling and narrative. Through storytelling, processes of change are envisioned and supported 
(Senehi, 2002). With the rise in nationalism across the globe, engaging the narrative becomes even more important. Anti-immigrant sentiments set the stage for the development of a negative context, increasing the risk of trauma in adjustment. Through story and empowering, strength-focused narrative can be highlighted while negative messages are contextualized and deflated.

Connecting with our own or others' stories of strength and resilience in the face of social upheaval, war, and trauma can be an antidote to what might otherwise be the internalization of a sense of powerlessness, depression, fear, or even shame.

(Senehi et al., 2009, p. 90)

Storytelling gives voice to the unique experience of intergroup and cross group conflict. It can also give voice to processes and pathways to change toward a place of peace (Senehi, 2002), and transformative change based in community narrative. The transformative change required to create sustainable communities that engage social, economic, political, and environmental justice requires a shift. Remediation and the building of resilience requires identifying strengths in individuals, families, and communities and mobilizing collective action through policy, advocacy, and/or community organizing.

The intersection of human systems, the ecology and physical space, and other wildlife creates a juncture for healing. As bell hooks (2008) reminds us through her storytelling, there is healing power through connection to the earth. In Belonging: A Culture of Place, hooks (2008) visualizes the mountains as the context of a sustainable and lush ecology, creating a love and warmth for deep connection to natural surroundings. She highlights a sense of belonging embedded in the natural ecology, and a deep connection with place-the "culture of place". hooks (2008) demonstrates a biophilia framework as she points out how nature becomes a teacher and healer if we listen. Through such a biophilia framework, we reconnect to the true position of human life within the context of nature, and thus are able to explore and engage in related healing processes that have been lost in modern life.

For example, when Muslim refugees from Somalia came to Lewiston, Maine in 2001, they were welcomed by some residents and feared by others because of their race and religion (Ellison, 2009). Lewiston was a decaying former mill town with large homes, low crime, and decent schools. Initially the level of hostility toward this new population rose. The new members of the community along with their allies stood non-violently in the face of violence. Over the years, they have built community businesses, rejuvenated the economy and the community, and connected to the land through farming. Their connection to the land and skills for farming have been shared as they build a new community embedded in place highlighting the link across community, biophilia, and identity. Similarly, Litfin (2014) underscores the link between community and sustainability as she explores the power of ecovillages across the globe. These communities create healing and sustainability as they operate at the juncture of the economic, ecological, and political context, particularly accounting for the significance of local control.

The value of regaining the lost connection with nature has the potential to help create a better life (hooks, 2008). We are challenged by hooks to consider the ways it is possible to live in a sustainable manner. 
Making peace with the earth we make the world a place where we can be one with nature. We create and sustain environments where we can come back to ourselves, where we can return home, stand on solid ground, and be a true witness. (hooks, 2008, pp. 25-26)

When she gives voice to a type of healing and peace that stops the exploitation of our earth, she pays tribute to the flora and fauna and the way all our lives are interconnected.

\section{Social Work: Interdisciplinary Partner}

As social work looks to address the global migrant crisis and mitigate environmental migration, we can be leaders in addressing the root problems of climate change and environmental degradation. If we are to promote sustainable communities and environments and support the resettlement of environmental migrants who have no hope of returning to their home, then it is critical that social workers who have not yet joined the professional agenda, be trained to work alongside those social workers who have taken up the fight to address the climate crisis. Social workers seeking to address the migrant crisis, by working as partners who engage in response systems alongside other professional disciplines and community members can help highlight the interconnections to the climate crisis.

Social work is a profession that operates in the nexus of multiple systems and disciplines, making it particularly well poised to address environmental migration as one piece of the complex migrant crisis. Social workers, trained to work across disciplines and within a collaboratively global context, bring a unique lens to practice in communities struggling with climate change and inadequate resources, such as those touched by the migrant crisis. These response systems can range from prevention and mitigation to resettlement and relief efforts to address climate change and environmental degradation. Social workers can also bring critical questions to the dialogue, such as: How does climate change and environmental degradation compound factors faced by vulnerable/marginalized people and communities? What ripple effects have been created by environmental migrants on their families, communities of origin, communities of resettlement, the ecosystem as a whole?

Social workers also have the knowledge and training for building the relationships needed to support environmental migrants in the building of capacity for empowerment, action, the forging of new links, and the establishing of working within relationships with a respect for differences. The profession has a rich history of working with communities as they form and re-form. Social work professionals can be a part of the capacity building that develops as groups move beyond intergroup and intragroup conflict to dialogue that explores multiple perspectives. As part of a multi-pronged response system for the migrant crisis and the related climate crisis, university-community collaborations can enrich the development by bringing together resources for the benefit of all. In addition, social workers enrich community/university coalitions (Schmitz, Matyók, Sloan, \& James, 2012), bringing resources to the work in community.

The biological and physical sciences have an extensive base of knowledge in the environmental sciences that focus on climate change; the social and human sciences have 
tended to lag behind (Schmitz, Stinson, \& James, 2010). This is shifting as the need for integrated responses to address the impact of climate change and environmental degradation on human communities and their social, economic, and political systems is being recognized. Besthorn and Saleeby (2003) underscore the alignment of social work with the biophilia framework. The indigenous biophilic framework is even more closely aligned with social work as it incorporates not only nature and place, but also community, oppression, and power dynamics (Cajete, 1999). Social workers and social work education are increasingly turning a focus toward recognizing climate change and environmental degradation and the related environmental injustices as having a major impact on human communities. Expanding to take an ecosystems perspective provides a framework for students to engage in practice the recognizes the adverse impact of climate change and environmental degradation (Schmitz et al., 2010) and the connections to the migrant crisis. Further complicating the issues is the tendency for professional disciplines to educate students in silos, poorly prepared for interdisciplinary responses (Orr, 2011). New methods are called for as we delve into problems which are multi-faceted by definition (Brown et al., 2010)

The complex and multilayered concerns of the migrant crisis cut across disciplines requiring education inclusive of the social and natural sciences, as well as indigenous knowledge. While Western science and education tend to emphasize compartmentalized, decontextualized knowledge, indigenous peoples have traditionally acquired knowledge through direct experience with the natural environment (Kawagley \& Barnhart, 1999). Williams and Hardison (2013) call for bringing scientists and indigenous peoples together to collaborate and exchange knowledge" (p. 531). "Our incapacity to deal with wicked problems...is related to their complexity, to the compartmentalization of scientific and professional knowledge" (Lawrence, 2010, p, 16). In addressing this shortcoming, it is important to integrate "the work of the academic disciplines with other forms of knowledge" (Lawrence, 2010, p. 17) through transdisciplinary inquiry and response, which we will use here as synonymous with interdisciplinary. Trandisciplinarity "is taken here to be the collective understanding of an issue; it is created by including the personal, the local and the strategic; as well as specialized contributions to knowledge" (Brown et al., 2010, p. 4). Thus, social workers operating with interdisciplinary partners have the experience and knowledge to be leaders in addressing the push toward and consequences of environmental migration at home, in transition, and upon resettlement.

\section{Conclusion}

As a profession, social work is mandated by our Global Agenda to promote community and environmental sustainability while also advocating for social and economic equality, the dignity and worth of all peoples, and attending to the importance of human relationships (IASSW, ICSW, \& IFSW, 2012). We are increasingly recognizing our interdisciplinary partnership role to become leaders in addressing the wicked problems of the climate crisis and the migrant crisis. Although we acknowledge that social work is addressing these issues of the migrant crisis, it is often done separately from addressing the intersecting issues of the climate crisis. Caught at the nexus of climate change and environmental deterioration, environmental migrants lack adequate support because the intersection is not 
recognized and validated. There are increasing numbers of social workers who do embrace the urgent need to address the climate crisis in their work, we are calling attention to the need to further train and encourage social workers to highlight the voices and needs of environmental migrants experiencing the impact of the climate crisis (Powers, 2016); climate change is the precipitating and compounding factor for the migration crisis.

In addition to working to mitigate climate change issues that cause displacement, helping rebuild and reestablish people in their homes of origin, promoting individual and community healing, and assisting with resettlement and building new lives, social workers can also be advocates to change the policies and laws to include environmental issues as justification for refugee status and thus increased aid. The United Nations' Sustainable Development Goals provides a framework through which we can increase our interdisciplinary responses as we work on climate advocacy and action, and address environmental migration. For example, social workers can help to mitigate environmental degradation and climate change by working to reduce toxins and promote clean water and sanitation, or working with urban planners to mitigate risks for vulnerable populations in case of disaster. In order to address environmental migration, social workers must engage in complex change systems which are holistic, multi-pronged, and inclusive of the biophysical environment and an indigenous biophilia framework and environmental migrants' voices and strengths. Understanding these connections and trying to address aspects of the biophysical context through an indigenous biophilia framework allows us to more critically analyze and mitigate the migrant crisis. Only then, can we hope to move forward, and address environmental migration.

\section{References}

Alston, M. (2013). Environmental social work: Accounting for gender in climate disasters. Australian Social Work, 66(2), 218-233. doi: https://doi.org/10.1080/0312407X.2012.738366

Atkin, E. (2017, September 20). Even before Hurricane Maria, Puerto Rico was already in environmental despair: A public health crisis looms. Retrieved October 07, 2017, from https://www.motherjones.com/environment/2017/09/climatedesk-nowhammered-by-hurricane-maria-puerto-rico-was-already-in-environmental-despair/

Balint, P. J., Stewart, R. E., Desai, A., \& Walters, L.C. (2011). Wicked environmental problems: Managing uncertainty and conflict. DC: Island Press. doi: https://doi.org/10.5822/978-1-61091-047-7

Besthorn, F. H., \& Meyer, E. (2010). Environmentally displaced persons: Broadening social work's helping imperative. Critical Social Work, 11(3), 123-138. Retrieved from http://www1.uwindsor.ca/criticalsocialwork/sites/uwindsor.ca.criticalsocialwork/files lcoates 8 pdf.pdf

Besthorn, F. H., \& Saleeby, D. (2003). Nature, genetics, and the biophilia connection: Exploring linkages with social work values and practice. Advances in Social Work, 4(1), 1-18. 
Black, R., Adger, W., Arnell, N. W., Dercon, S., Geddes, A., \& Thomas, D. (2011). The effect of environmental change on human migration. Global Environmental Change, 21(1), S3-S11. doi: https://doi.org/10.1016/j.gloenvcha.2011.10.001

Bradshaw, T. K. (2009). Theories of poverty and anti-poverty programs in community development. Community Development, 38(1), 7-25. doi: https://doi.org/10.1080/15575330709490182

Brown, O. (2008). Climate change and forced migration: Observations, projections and implications. Human Development Report 2007/2008, Fighting climate change: Human solidarity in a divided world. Retrieved October 22, 2016, from https://www.iisd.org/pdf/2008/climate_forced_migration.pdf

Brown, V. A. (2010). Collective inquiry and its wicked problems. In V. A. Brown, J. A. Harris, \& J. Y. Russell (Eds.), Tackling wicked problems: Through the transdisciplinary imagination (pp. 61-83). New York: Earthscan.

Brown, V. A., Deane, P. M., Harris, J. A., \& Russell, J. Y. (2010). In V. A. Brown, J. A. Harris, \& J. Y. Russell (Eds.), Tackling wicked problems: Through the transdisciplinary imagination (pp. 3-15). New York: Earthscan.

Cajete, G. (1999). Reclaiming biophilia: Lessons from Indigenous people. In G. A. Smith \& D. R. Williams (Eds.), Ecological education in action: On weaving education, culture, and the environment (pp. 189-206). Albany, NY: State University of New York Press.

Canty, J. M. (Ed.). (2017). Ecological and social healing: Multicultural women's voices. New York: Routledge.

Colomeda, L.A.L. (1999). Keepers of the central fire: Issues of ecology for Indigenous people. Sudsbury, MA: Jones and Bartlett.

Cook, J., Oreskes, N., Doran, P. T., Anderegg, W. R. L., Verheggen, B., Maibach, E. W....Rice, K. (2016). Consensus on consensus: A synthesis of consensus estimates on human-caused global warming. Environmental Research Letters, 11(4), 1-7. doi: https://doi.org/10.1088/1748-9326/11/4/048002

Council on Social Work Education [CSWE]. (2015). Educational Policy and Accreditation Standards and Glossary. Alexandria, VA: Author. Retrieved from https://www.cswe.org/getattachment/Accreditation/Standards-and-Policies/2015EPAS/2015EPASandGlossary.pdf.aspx

Deepak, A. C. (2018). Postcolonial feminist social work perspective: Additional considerations for immigrant and refugee populations. In A. Hilado \& M. Lundy (Eds.), Models for practice with immigrants and refugees: Collaboration, cultural awareness, and integrative theory (pp. 113-124). Los Angeles, CA: Sage.

Devore, W., \& Schlesinger, E. G. (1998). Ethnic-sensitive social work practice (5th ed.). Boston, MA: Allyn \& Bacon. 
Drolet, J. (2017). Forced migration and the lived experiences of refugees. In M. Rinkel \& M. Powers (Eds.), Social work promoting community and environmental sustainability: A workbook for social work practitioners and educators (pp.192-201). Switzerland: International Federation of Social Work [IFSW]. Retrieved from http://ifsw.org/product/books/social-work-promoting-community-and-environmentalsustainability-free-pdf/

Ellis, H. B., \& Abdi, S. (2017). Building community resilience to violent extremism through genuine partnerships. American Psychologist, 72(3), 289-300. doi: https://doi.org/10.1037/amp0000065

Ellison, J. (2009, January 16). The refugees who saved Lewiston. Newsweek Magazine. Retrieved from https://www.newsweek.com/lewiston-maine-revived-somaliimmigrants-78475.

Gamble, D. N., \& Weil, M. (2010). Community practice skills: Local to global. New York: Columbia University Press.

Garner, R. (2015, August 26). Warming seas, melting ice sheets. Retrieved October 04, 2017, from https://www.nasa.gov/feature/goddard/warming-seas-and-melting-icesheets

hooks, b. (2008). Belonging: A culture of place. Hoboken: Taylor \& Francis.

Hutchinson, A-M. K., Stuart, A. D., \& Pretorius, H. G. (2010). Biological contributions to well-being: The relationships amongst temperament, character strengths and resilience. South African Journal of Industrial Psychology, 36(2), 1-10. doi: https://doi.org/10.4102/sajip.v36i2.844

International Association of Schools of Social Work, International Council on Social Welfare, and International Federation of Social Workers [IASSW, ICSW, \& IFSW]. (2012). The global agenda for social work and social development: Commitment to action. Retrieved November 17, 2015, http://cdn.ifsw.org/assets/globalagenda2012.pdf

IFSW. (2017). High level political forum 2017, United Nations, New York Workshop to promote Social Workers Role for reaching the Sustainable Development Goals (SDGs). Retrieved September 4, 2017, from http://ifsw.org/news/high-level-politicalforum-2017-united-nations-new-york-workshop-to-promote-social-workers-role-forreaching-the-sustainable-development-goals-sdgs/

Intergovernmental Panel on Climate Change [IPCC]. (2015). Climate change 2014: Mitigation of climate change: Summary for policymakers. Retrieved from https://www.ipcc.ch/pdf/assessmentreport/ar5/wg3/WGIIIAR5_SPM_TS_Volume.pdf

International Organization for Migration [IOM]. (2015). Terminology on migration, environment and climate change. In IOM outlook on migration, environment and climate change (pp. 21-24). NY: UN Publications. doi: https://doi.org/10.18356/14b2ac9d-en 
IOM. (2018a). Definitional issues. Retrieved June 15, 2017, from https://www.iom.int/definitional-issues

IOM. (2018b.). Migration and climate change: What are the estimates? Retrieved from https://www.iom.int/migration-and-climate-change-0

Kawagley, A., \& Barnhart, R. (1999). Education indigenous to place: Western science meets Native reality. In G. A. Smith \& R. W. Dilafruz (Eds.), Ecological education in action: On weaving education, culture, and the environment (pp. 117-140). Albany, NY: State University of New York Press.

Kellert, S. R., \& Wilson, E. O. (Eds.). (1995). The biophilia hypothesis (reissue ed.). DC: Shearwater/Island Press.

Kelley, C. P., Mohtadi, S., Cane, M. A., Seager, R., \& Kushnir, Y. (2015). Climate change in the Fertile Crescent and implications of the recent Syrian drought. Proceedings of the National Academy of Sciences, 112(11), 3241-3246. doi: https://doi.org/10.1073/pnas.1421533112

Kolko, J. (2012). Wicked problems: Problems worth solving. Austin, TX: Austin Center for Design.

Lawrence, R. J. (2010). Beyond disciplinary confinement to imaginative transdisciplinarity. In V.A. Brown, J.A. Harris, \& J.Y. Russell. Tackling wicked problems: Through the transdisciplinary imagination (pp. 16-30). New York: Earthscan.

Lederach, J. P., \& Lederach, A. J. (2010). When blood and bones cry out: Journeys through the soundscape of healing and reconciliation. Oxford, NY: Oxford University Press.

Lie, G.-Y., \& Lowery, C. T. (2003). Cultural competence with women of color. In D. Lum (Ed.), Culturally competent practice: A framework for understanding diverse groups and justice issues (2nd ed., pp. 282-309). Pacific Grove, CA: Brooks/Cole.

Litfin, K. T. (2014). Ecovillages: Lessons for sustainable community. United Kingdom: Polity Press.

Lysack, M. (2010). Environmental decline, loss, and biophilia: Fostering commitment in environmental citizenship. Critical Social Work, 11(3), 48-66.

Maathai, W. (2003). The Green belt movement: Sharing the approach and the experience. New York, NY: Lantern Books.

Maathai, W. (2004). Wangari Maathai - Nobel Lecture. Retrieved from www.nobelprize.org/nobel_prizes/peace/laureates/2004/maathai-lecture-text.html

McLean, K. G. (2010). Advance guard: Climate change impacts, adaptation. Mitigation and Indigenous Peoples. NY: United Nations University.

Merton, L., \& Dater, A. (Producers and Directors). (2008). Taking root: The vision of Wangari Maathai [DVD]. United States: Marlboro Productions. 
Norgaard, K.M., \& Reed, R. (2017). Emotional impacts of environmental decline: What can Native cosmologies teach sociology about emotions and environmental justice. Theory and Society, 46, 463-495. doi: https://doi.org/10.1007/s11186-017-9302-6

Opido, G., Odwe, G., Oulu, M., \& Omollo, E. (2017). Migration as adaptation to environmental and climate change: The case of Kenya. Kenya: IOM.

Orr, D. W. (2004). Earth in mind: On education, environment, and the human prospect. DC: Island Press.

Orr, D. W. (2011). Down to the wire: Confronting climate collapse. Washington, D.C.: Island Press.

Packer, R. K. (2002). How long can the average person survive without water? Retrieved October 04, 2017, from https://www.scientificamerican.com/article/how-long-canthe-average/

Parry, M., Canziani, O., Palutikof, J., Linden, P. V., \& Hanson, C. (2007). Climate change 2007 - impacts, adaptations and vulnerability. Cambridge: Cambridge University Press. Retrieved from https://www.ipcc.ch/pdf/assessmentreport/ar4/wg2/ar4_wg2_full_report.pdf

Powers, M. C. F. (2016). Transforming the profession: Social workers' expanding response to the environmental crisis. In A.-L. Matthies \& K. Narhi (Eds.), Ecosocial transition of societies: Contribution of social work and social policy. New York: Routledge.

Powers, M. C. F., \& Nsonwu, C. (in press). Environmental injustices faced by resettled refugees: Housing policies and community development. In R. Hugman, J. R. Drolet, J. \& S. Todd (Eds.) Community practice and social development in social work: Major research works. NSW, AUS: Springer Nature.

Rabb, H. (2017). Sustainable wellbeing and social work with children: Promoting our connectedness with nature through Nature- Assisted interventions. In M. Rinkel \& M. Powers (Eds.), Social work promoting community and environmental sustainability: A workbook for social work practitioners and educators (pp. 133145). Switzerland: IFSW. Retrieved from http://ifsw.org/product/books/social-workpromoting-community-and-environmental-sustainability-free-pdf/

Reuters and The Associated Press. (2017, April 16). Hundreds feared buried in Sri Lanka rubbish dump landslide. Retrieved October 06, 2017, from https://www.theguardian.com/world/2017/apr/16/hundreds-feared-buried-in-srilanka-rubbish-dump-landslide

Schmitz, C. L., Matyók, T., Sloan, L., \& James, C. D. (2012). The relationship between social work and environmental sustainability: Implications for interdisciplinary practice. International Journal of Social Work, 21(3), 278-286. doi: https://doi.org/10.1111/j.1468-2397.2011.00855.x 
Schmitz, C. L., Stinson, C. H., \& James, C. D. (2010). Community and environmental sustainability: Collaboration and interdisciplinary education. Critical Social Work, 11(3), 83-100.

Schmitz, C. L., Vazquez Jacobus, M., Stakeman, C., Valenzuela, G., \& Sprankel, J. (2003). Immigrant and refugee communities: Resiliency, trauma, and social work practice. Social Thought, 22(2/3), 135-158. doi: https://doi.org/10.1300/J131v22n02_10

Senehi, J. (2002). Constructive storytelling: A peace process. Peace and Conflict Studies, 9(2), 41-63.

Senehi, J., Flaherty, M., Kirupakaran, C. S., Kornelsen, L., Matenge, M., \& Skarlato, O. (2009). Dreams of our grandmothers: Discovering the call for social justice through storytelling. Storytelling, self, society: An interdisciplinary journal of storytelling studies, 5(2), 90-106.

Soylu, A., \& Buchanon, T. A. (2013). Ethnic and racial discrimination against immigrants. Journal of Business and Economics, 4(9), 8548-8581.

Spurlin, W. J. (2010). Resisting heteronormativity/resisting recolonisation: Affective bonds between indigenous women in southern Africa and the difference(s) of postcolonial feminist history. Feminist Review, 95(95), 10-26. doi: https://doi.org/10.1057/fr.2009.56

Strides in Development. (2010, July 9). Wangari Maathai \& the green belt movement . [Video file]. Retrieved from https://m.youtube.com/watch?v=BQU7JoxkGvo

Sustainable Human. (2014, February 13). How wolves change rivers. Retrieved October 07, 2017, from https://www.youtube.com/watch?v=ysa5OBhXz-Q

Taylor, M. (2017, November 2). Climate change 'will create world's biggest refugee crisis. The Guardian. Retrieved February 1, 2018, from https://www.theguardian.com/environment/2017/nov/02/climate-change-will-createworlds-biggest-refugee-crisis

UN Environment. (2016). Annual report 2016: Engaging people to protect the planet. Retrieved from https://www.unenvironment.org/annualreport/2016/?page=0\&lang=en

United Nations High Commission on Refugees [UNHCR]. (2009). Climate change, natural disasters and human displacement: a UNHCR perspective. Retrieved from www.unhcr.org/4901e81a4.html

UNHCR. (2016, November 6). Frequently asked questions on climate change and disaster displacement. Retrieved June 15, 2017, from http://www.unhcr.org/enus/news/latest/2016/11/581f52dc4/frequently-asked-questions-climate-changedisaster-displacement.html)

UN Trust Fund for Human Security. (n.d.). Human security: Building resilience to climate threats. Retrieved October 4, 2017, from 
https://www.un.org/humansecurity/wp-content/uploads/2017/10/Human-Securityand-Climate-Change-Policy-Brief-1.pdf

United Nations Women Watch. (2009). Women, gender equality and climate change. Retrieved October 4, 2017, from

http://www.un.org/womenwatch/feature/climate change/downloads/Women and Cli mate Change Factsheet.pdf

Watkins, A., \& Wilber, K. (2015). Wicken \& wise: How to solve the world's toughest problems. Great Britain: Urbane Publications.

Welch, C. (2015, March 02). Climate change helped spark Syrian War, study says. Retrieved September 28, 2017, from http://news.nationalgeographic.com/news/2015/03/150302-syria-war-climatechange-drought/

Weng, S. S., \& Lee, J. S. (2016). Why do immigrants and refugees give back to their communities and what can we learn from their civic engagement? VOLUNTAS: International Journal of Voluntary and Nonprofit Organizations, 27(2), 509-524. doi: https://doi.org/10.1007/s11266-015-9636-5

Williams, T., \& Hardison, P. (2013). Culture, law, risk and governance: Contexts of traditional knowledge in climate change, 120(3), 531-544.

Wilson, E. O. (1984). Biophilia. Cambridge, Mass: Harvard University Press.

Author note: Address correspondence to: Meredith C.F. Powers, PhD, Department of Social Work, School of Health and Human Sciences, University of North Carolina at Greensboro, 259 Stone Building, Greensboro, NC 27402-6170. MCFPowers@ uncg.edu 